\title{
FRACTURE TOUGHNESS TESTING OF ROCK WITH CORE BASED SPECIMENS
}

\author{
FINN OUCHTERLONY \\ ISRM Working Group Coordinator, Swedish Detonic Research Foundation, SveDeFo, \\ P.O. Box 32058, S-12611 Stockholm, Sweden
}

\begin{abstract}
The fracture toughness testing of rock with core based specimens is reviewed with an emphasis on specimens with chevron shaped notches. The development of such specimens and the early testing experience is described. It led to the formation of a working group within the ISRM which has now produced two "Suggested Methods for Determining the Fracture Toughness of Rock", one using the Chevron Bend specimen and the other the Short Rod. An outline of these Suggested Methods and the evaluation procedure involved is given. Then supporting specimen calibration work and fracture toughness testing are described. Finally parallel development is briefly mentioned. In conclusion, it appears that the two specimens in the ISRM Suggested Methods can produce fracture toughness values which are independent of specimen size and which are compatible both with each other and with values from other tests as well.
\end{abstract}

\section{INTRODUCTION}

ROCK FRACTURE mechanics has been a recent topic of several monographs[1-3]. Early fracture toughness testing of rock is covered in greater depth by Ouchterlony[4]. This testing employed a wide variety of specimen types and test methods, usually developed for metals or ceramics, and the resulting values were generally not compatible[4-6].

The fracture toughness of a material expresses its resistance to (catastrophic) crack extension (propagation), or the fracture surface energy consumption rate required to create new surfaces. The three common representations, stress intensity $\left(K\right.$ in Pa $\sqrt{\mathrm{m}}$ or $\left.\mathrm{N} / \mathrm{m}^{1.5}\right), J$-integral $\left(J\right.$ in $\mathrm{J} / \mathrm{m}^{2}$ or $\mathrm{N} / \mathrm{m})$ and specific work of fracture $\left(\bar{R}\right.$ or $G_{\mathrm{F}}$ in $\left.\mathrm{J} / \mathrm{m}^{2}\right)$ all have slightly different theoretical justifications and hence differently focused test methods.

Some conclusions of the earlier work were[4] that:

1. $K_{\mathrm{lc}}$ testing for metals as per ASTM E399† seemed to be effective for rock. In plane specimen size requirements were important to meet but thickness and loading rate had little effect on the tentative results $\left(K_{\mathrm{Q}}\right)$.

2. An approximate fracture toughness evaluation using notched but not precracked specimens (cores) usually gave results that were too low.

3. The Short Rod evaluation (core based), including a certain non-linearity correction, could give acceptable results.

4. A $J_{\mathrm{lc}}$ evaluation modelled on ASTM E813 also seemed effective for rock. It required smaller specimens than $K_{\mathrm{Ic}}$ testing to give acceptable results.

5. None of the other crack resistance parameters appeared to be compatible with the specific work of fracture.

Clearly, the use of core based specimen types had already started. Rock is often available in the form of core pieces. If not, their coring is a standard operation and the use of such cores minimizes the remaining machining required.

The need for standardized testing methods had also become obvious. An ideal method would give a representative fracture toughness value and yet be simple, i.e. require neither precracking, nor crack length or displacement measurements, nor sophisticated evaluation techniques, all of which make metals testing according to E399, e.g. cumbersome. Chevron notched specimens appeared to fulfil many of these requirements. 


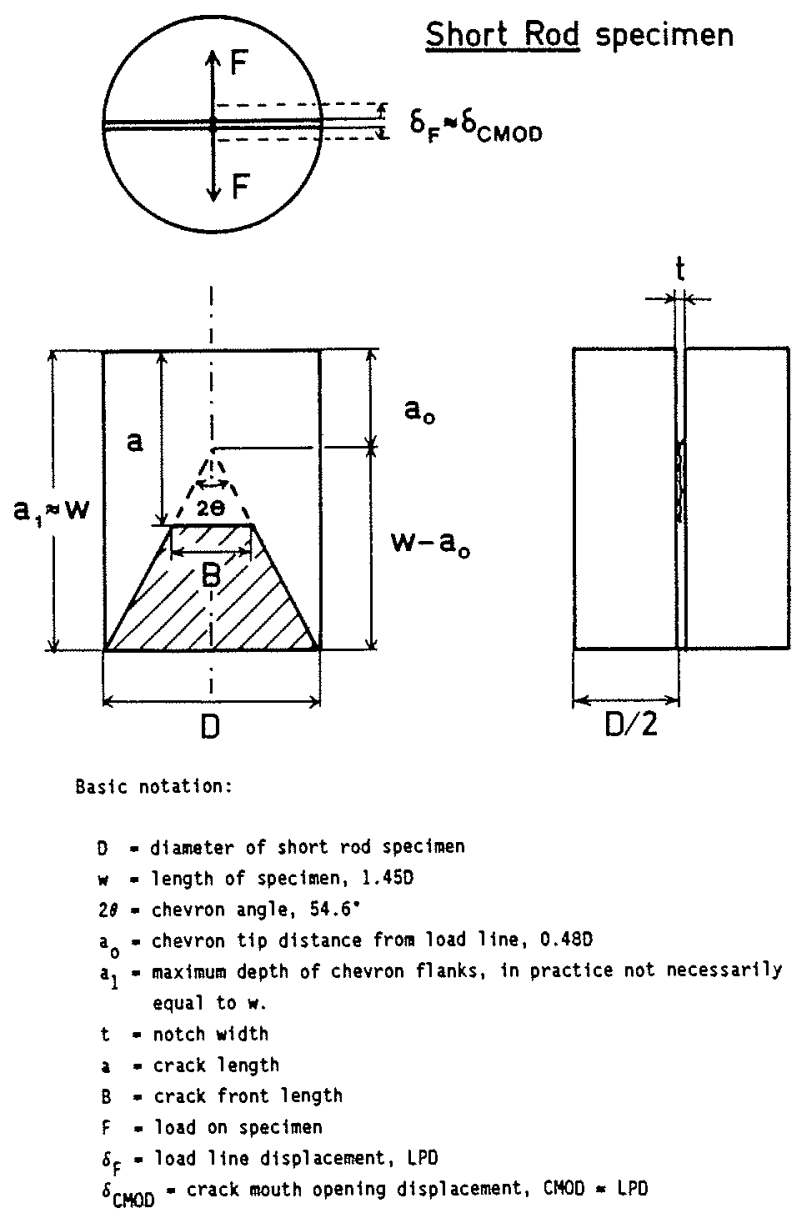

Fig. 1. The Short Rod (SR) specimen with basic notation.

\section{DEVELOPMENT OF CORE BASED SPECIMENS}

The Short Rod is a core based specimen type which was introduced by Barker[7] in 1977. The idealized geometry is shown in Fig. 1. In contrast to most earlier fracture toughness testing specimens it has a chevron notch rather than a straight one, such that when the crack grows the length of the crack front increases.

A set of characteristic stress intensity factor curves for the Short Rod is shown in Fig. 2 together with a material curve showing the crack extension resistance (fracture toughness) as having reached a constant, representative level. The former curves have a minimum at a specific crack length, $a=a_{\mathrm{m}}$ say. Up to this point the crack extension is stable due to the chevron notch and achieved by a steadily increasing load. During this period a sharp natural crack is created in the specimen. Beyond $a_{\mathrm{m}}$ the crack extension tends to become unstable.

Hence, ideally, all one would have to do during a test is to read off $F_{\max }$ corresponding to the tangency condition and determine the fracture toughness from

$$
K_{\mathrm{SR}}=K_{1}\left(a_{\mathrm{m}}, F_{\max }\right)=K_{\mathrm{lmin}}\left(F_{\max }\right)=A_{\min } F_{\max } / D^{1.5} .
$$

Barker[7] gave the value of $A_{\min }$ as 20.8. Since the critical crack length is determined by specimen geometry alone, crack length measurements would appear to be unneccessary. The price of this simplicity is that the assumption of a constant representative toughness level remains unverified.

Barker's revival of the chevron notched specimen started a wave of similar specimen calibration work (e.g. see Newman[8]), much of it focused on the Short Rod (see Fig. 3). After 


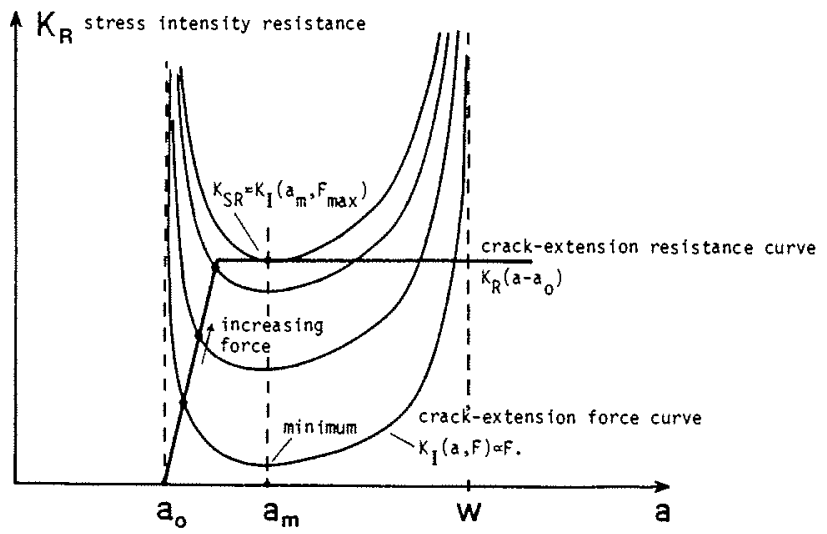

Fig. 2. Principal appearance of the stress intensity factor (crack extension force) curve $K_{\mathrm{I}}(a, F)$ of the Short Rod specimen. A crack extension resistance curve $K_{\mathrm{R}}\left(a-a_{0}\right)$ with flat upper part (representative toughness level) is assumed in $K_{\mathrm{SR}}$ evaluation in eqn. (1).

careful screening of the available work, a consensus value corresponding to

$$
A_{\min }=24.00 \pm 0.25
$$

was arrived at for a specimen with the proportions $w / D=1.45$ and $a_{0} / D=0.48$. Due to the extent of the underlying work, these proportions would also become guidelines for rock testing.

Two of the calibration methods used, $K_{\mathrm{Ic}}$ matching and the STC approximation, were cautioned against[8]. $K_{\mathrm{Ic}}$ matching implies using the same material in two different test methods with one (e.g. ASTM E399) as a reference. The STC approximation is simply the assumption that the rate of change of compliance with crack length in a chevron notched specimen should equal the value in a similar specimen without this notch but with a straight-through-crack (STC).

Two other calibration methods, numerical three-dimensional elasticity solutions, e.g. by finite or boundary elements, and experimental compliance measurements were both considered to yield accurate results. According to Bubsey et al.[9] the latter method is generally less precise than refined numerical methods but it has the advantage of that the boundary conditions can be (and should be) practically the same as those in the actual testing situation. Numerical methods, at least before, suffered from the necessity of simplifying the boundary conditions to make the problem tractable.

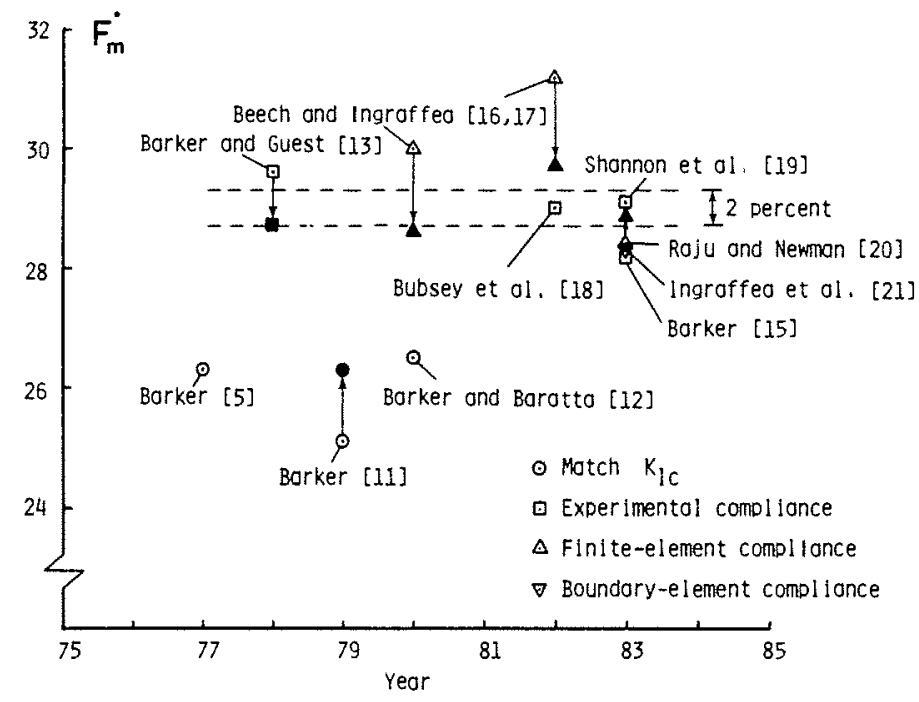

Fig. 3. Development of minimum normalized stress intensity factor values $F_{\mathrm{m}}^{*}$ for Short Rod leading to consensus value. After Newman[8] where references are given. Note that $A_{\min }=F_{\mathrm{m}}^{*} / \sqrt{ }(w / D)=0.830 \cdot F_{\mathrm{m}}^{*}$ since $w / D=1.45$, c.f. eq. (2). 


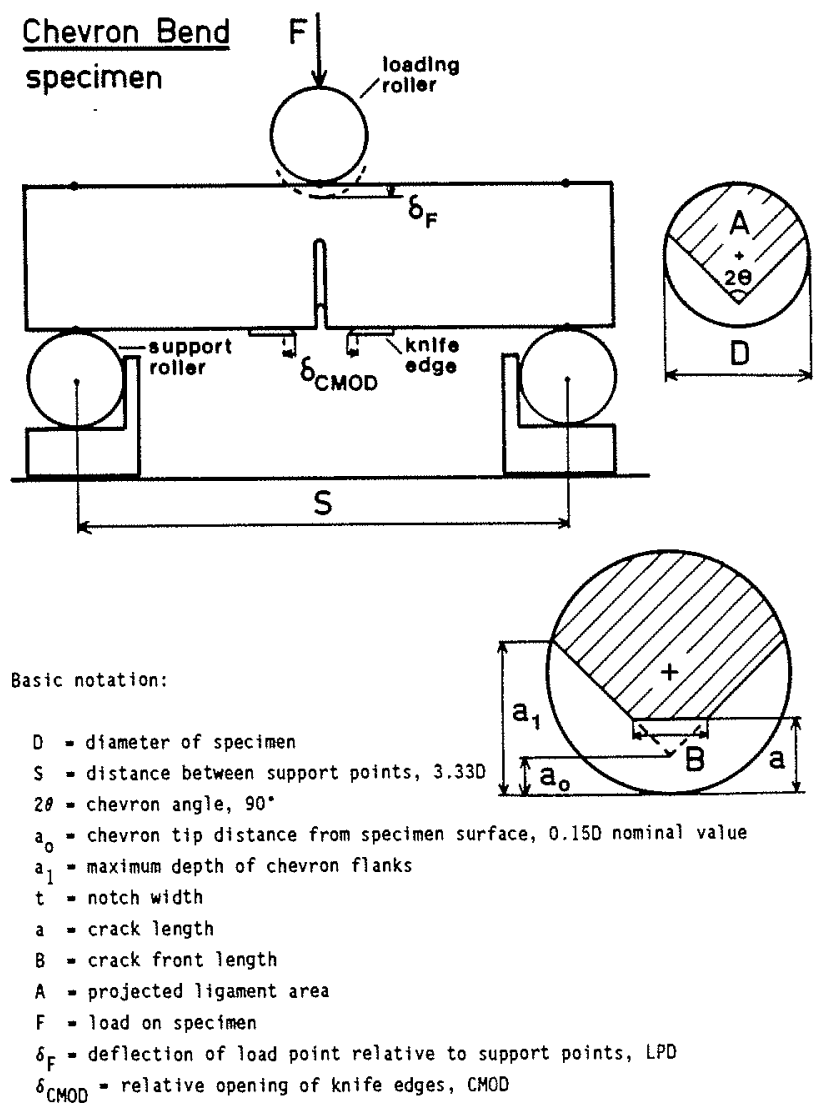

Fig. 4. The Chevron Bend (CB) specimen with bend test fixture and basic notation.

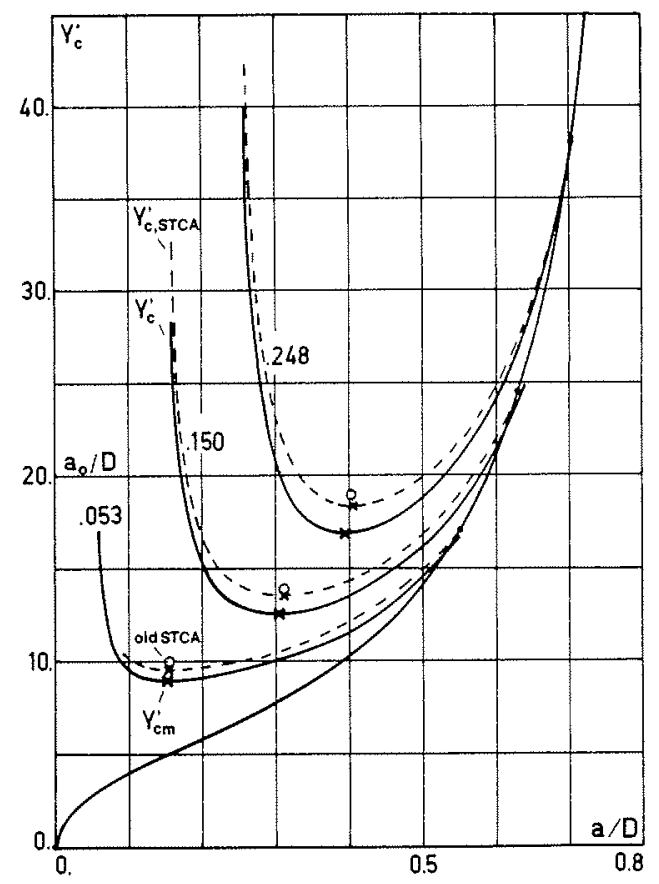

Fig. 5. Plot of normalized stress intensity factor curves $Y_{\mathrm{c}}^{\prime}$ vs crack length ratio for Chevron Bend specimens with notch apex ratios $a_{0} D=0.053,0.150$ and 0.248 . Note that $A_{\mathrm{min}}=0.25(S / D) \cdot Y_{\mathrm{cm}}^{\prime}=0.8325 \cdot \mathrm{Y}_{\mathrm{cm}}^{\prime}$ since $S / D=3.33$. After Ouchterony[13]. 
Meanwhile Ouchterlony[10-13] had worked on the development of two core specimens with transverse notches for three point bending, first one with a straight notch and then another with a chevron notch (see Figs 4 and 5). Based on extensive compliance measurements, formulas for stress intensity, for the $J$-integral, for stability functions and for modulus measurements were developed and used in testing.

As a result of this experience an international working group (WG) on the fracture toughness testing of rock was formed within the ISRM Commission on Testing Methods at Swedish initiative in 1983. Its purpose was to develop a Suggested Method for such testing, i.e. a method which would consistently yield accurate fracture toughness values and which could become an accepted international standard.

At this time there did of course exist other cylindrical specimen types which had been used in the fracture toughness testing of rock (e.g. see[14-16]). The members of the WG focused their interest on the Short Rod and the Chevron Bend specimen however, because their experience related to these specimens and because testing specimens with chevron notches appeared to be simple in that neither fatigue precracking, nor perhaps crack length or displacement measurements, seemed necessary to make.

\section{EARLY EXPERIENCE WITH CHEVRON NOTCHED TESTING}

A test method which is designed to measure a material property should of course give a result which is reasonably independent of the test conditions. Hence it is always associated with a number of acceptance limits on these.

In linear elastic fracture mechanics testing (LEFM, E399 related) an important requirement concerns specimen size, crack length $(a)$ and ligament width $(D-a$ or $w-a)$ must fulfil

$$
a, w-a \geqslant a_{\min }=2.5 \cdot\left(K_{\mathrm{lc}} / \sigma_{\mathrm{t}}\right)^{2} .
$$

Here the tensile strength $\sigma_{\mathrm{t}}$ may be used for rock[4]. In developing a new test method, the establishing of a similar limit where the measured fracture toughness values become size independent is equally important.

Similarly a compatibility between results obtained with a new method and those of a proven old method gives credence to the new method, as does the compatibility between results obtained with new methods prescribing the use of different specimen types.

Typical inferred LEFM size requirements for rocks tested by Ouchterlony and Sun[17] were $a_{\min } \geqslant 125 \mathrm{~mm}$ and $D_{\min }$ or $w_{\min } \geqslant 250 \mathrm{~mm}$, making normal core sizes subsize in comparison. They $[12,18,19]$ tried several methods to obtain representative fracture toughness values from subsize core based specimens. Some of these were successful, e.g. an E399 related one denoted $K_{\mathrm{Qm}}$ and a $J$-integral related one based on $R$-curves, but they required extensive displacement measurements and associated crack length evaluations from relatively obscure compliances[17].

Barker's work [20] showed that Short Rod toughness values for Indiana limestone, $\left(K_{\mathrm{SR}}\right)$ evaluated from eq. (1), depended on specimen size. He viewed this as an effect of a nonnegligible microcrack zone around the crack tip and developed a "plasticity" correction procedure to account for it $[20,21]$. This procedure has been adopted by the ISRM WG and it is shown below in Section 4. The values are denoted $K_{\mathrm{SR}}^{\mathrm{c}}$ and contain a correction factor for nonlinear material behaviour, $p$ (see eqs 13-15).

Barker's[20] data for Indiana limestone and Sun's[19] for Stripa granite showed that $K_{\mathrm{SR}}^{\mathrm{c}}$ was independent of specimen size, even when $D \approx 25 \mathrm{~mm}$ and $p \approx 0.4$. Furthermore this toughness level agreed well with E399 based toughness values for the same rocks. This conclusion also held for $D \approx 69 \mathrm{~mm}$ specimens of oil shale (see Costin[22] and Fig. 6). Meredith[23] on the other hand obtained good agreement between $K_{\mathrm{SR}}$ and $K_{\mathrm{SR}}^{\mathrm{c}}$ data from $D \approx 25 \mathrm{~mm}$ specimens with fracture toughness values obtained with the double torsion test method (see Fig. 7).

In other words it appeared that a correction of the $K_{\mathrm{SR}}$ evaluation was necessary in order to obtain representative fracture toughness values from specimens made of normal core sizes[17]. $K_{\mathrm{SR}}$ measurements by Ingraffea et al.[24] on Indiana limestone and Westerly granite tended to support this conclusion. 


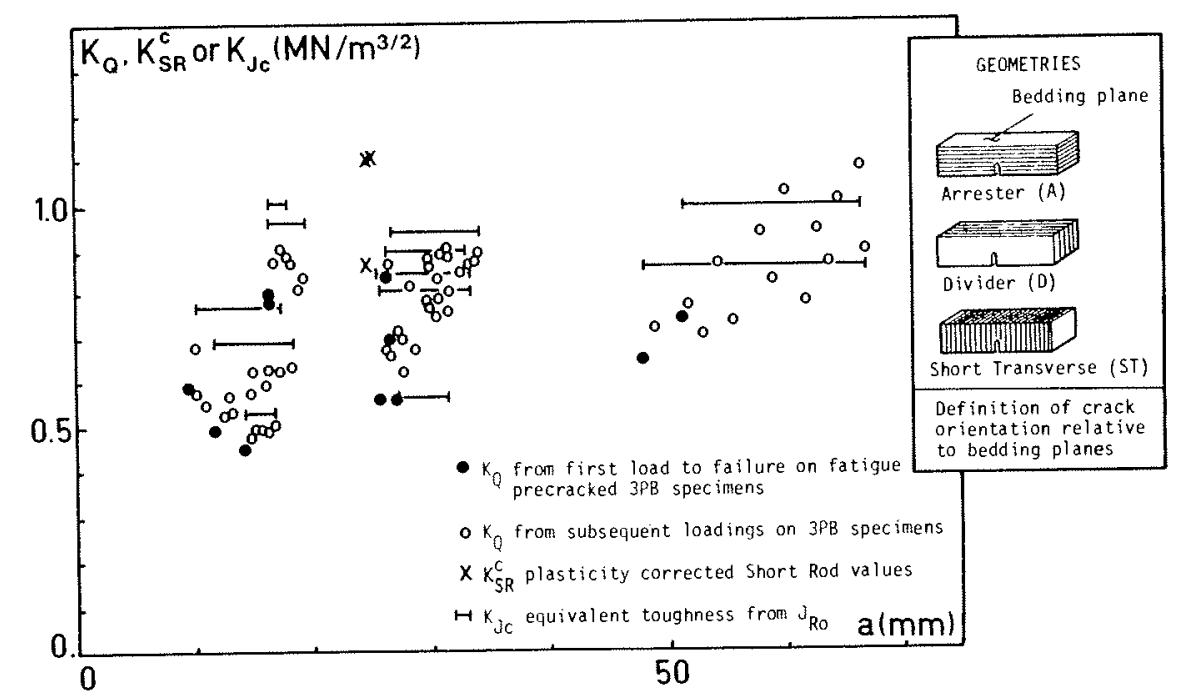

Fig. 6. Comparison of different stress intensity measures of fracture toughness for oil shale, plotted vs crack length. From Costin[22] and Ouchterlony[4].

Since this correction requires both force and load point displacement measurements to be made continuously during the testing, the chevron notched specimens did not quite live up to the expectations. However, for some rocks uncorrected fracture toughness values from chevron notched specimens came quite close to a representative level, and always much closer than values based on specimens with straight notches on which no displacement measurements were made[17].

The prevalent anisotropy of rock material could be important in the fracture toughness testing of $\operatorname{rock}[5,12]$. Even if anisotropic stress intensity factors normally would differ relatively little from their isotropic counterparts, treating the conversion from $K$ to $J$ (or vice versa) as isotropic could incur larger errors. Based on the work of Costin[22] and others on oil shale (reviewed in[12]), it appears quite reasonable to expect good agreement between stress intensity resistance and $J$-integral values if this conversion is made correctly.

A conclusion drawn in[12] was that matching elastic moduli and strength properties should always accompany crack resistance data so that specimen size criteria and anisotropy effects can

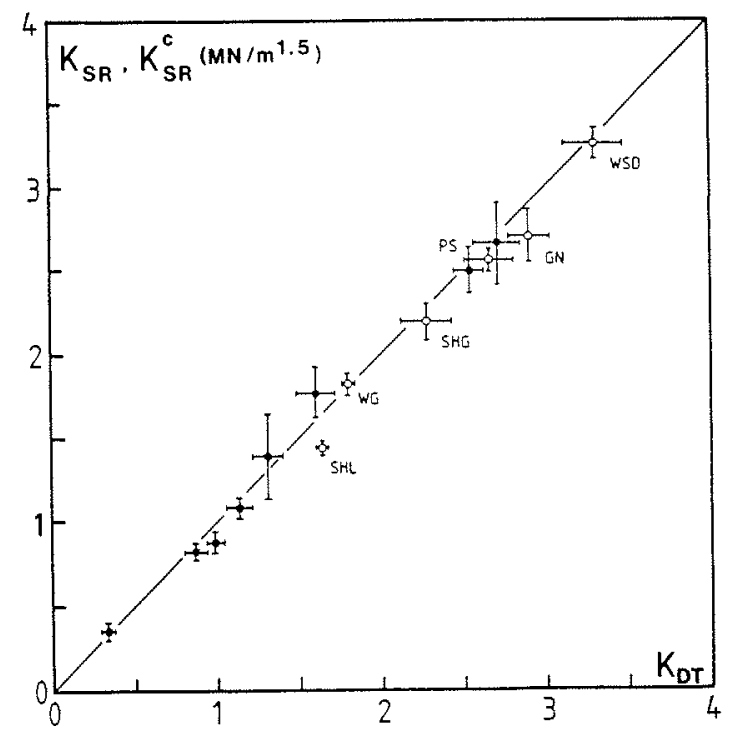

Fig. 7. Compatibility of fracture toughness values from Short Rod tests with values from double torsion (DT) tests on 14 rocks. Open circles denote $K_{\mathrm{SR}}^{\mathrm{c}}$ and full circles $K_{\mathrm{SR}}$ values. After Meredith[23]. 
be evaluated. New standard methods for the fracture toughness testing of rock could however hardly incorporate anything but the isotropic calibration of $A_{\min }$, at least not until they have been thoroughly evaluated.

\section{AN OUTLINE OF THE ISRM SUGGESTED METHODS}

The working group within ISRM has now finalized two "Suggested Methods (SM:s) for Determining the Fracture Toughness of Rock." The document[25] specifies the use of the Chevron Bend specimen of Fig. 4 and the Short Rod of Fig. 1.

The use of two specimens with different crack orientations permits an assessment of fracture anisotropy from one core while saving core material, since the bend specimen is long enough for the halves remaining after testing to be used for Short Rod testing.

Two levels of testing are offered in each method, giving the prospective user a choice between accuracy and cost. Level I requires only a registration of maximum load to be made during the test. Level II requires continuous load and displacement measurements to be made during the test.

While level I testing is simple and cheap, yielding index like results, level II testing is more complicated. Since level I testing of normal core sizes tends to yield fracture toughness values which are lower than values obtained from larger specimens, but level II testing in some cases yields values that are independent of core size and that correlate well with results from other test methods, level II testing is sometimes justified.

The SM:s follow other ISRM Suggested Methods closely, the general contents are:

GENERAL INTRODUCTION.

TECHNICAL INTRODUCTION: On Fracture Mechanics. On the Concept of Fracture Toughness, On the Use of Fracture Toughness Testing for Rock, Purpose of these Suggested Methods, On the Suggested Methods, References.

METHOD 1: Suggested Method for Determining Fracture Toughness Using Chevron Bend Specimens.

METHOD 2: Suggested Method for Determining Fracture Toughness Using Short Rod Specimens.

NOTES.

BIBLIOGRAPHY.

Each SM contains detailed specifications of testing, as, for example, in Method 1 (Chevron Bend Testing),

Scope.

Specimen Description.

Apparatus: Specimen Preparation Equipment, Testing Machine and Load Fixtures, Specimen Alignment Aids, Displacement Measuring Equipment, Recording.

Procedure: Specimen Selection and Preparation, Calibration, Setting Up, Testing.

Calculations: Calculation of Loading Rate, Calculation of Slope Values, Calculation of Fracture Toughness, Correction of Fracture Toughness for Non-linearity, Calculation of Additional Quantities (Young's Modulus, Energy Rate Resistance and Specific Work of Fracture).

Validity: Specimen Size and Type, Use of Fracture Toughness Values.

Reporting Results: General Data, Test Sample Data, Specimen Data. possible.

The specifications concerning Method 2 (Short Rod testing) are of course as identical as

The background on the evaluation formulas used in the SM:s are given by Ouchterlony [26].

The specified proportions of the Chevron Bend specimen in Method 1 are, including tolerances,

$$
\begin{aligned}
S & =3.33 D \pm 0.02 D, \text { or }|\Delta S| \leqslant 0.02 D \\
a_{0} & =0.15 D \pm 0.10 D, \\
2 \theta & =90.0^{\circ} \pm 1.0^{\circ}, \text { and } \\
t & \leqslant 0.03 \mathrm{D} \text { or } 1 \mathrm{~mm}, \text { whichever is greater. }
\end{aligned}
$$


(See Fig. 4 for notation.) The specified proportions of the Short Rod specimen in Method 2 are

$$
\begin{aligned}
w & =1.45 D \pm 0.02 D, \quad \text { or }|\Delta w|=\leqslant 0.02 D, \\
a_{0} & =0.48 D \pm 0.02 D, \\
a_{1}-a_{0} & =0.97 D \pm 0.02 D, \\
2 \theta & =54.6^{\circ} \pm 1.0^{\circ} \text { and } \\
t & \leqslant 0.03 D \text { or } 1 \mathrm{~mm}, \text { whichever is greater. }
\end{aligned}
$$

(See Fig. 1 for notation.) The tolerances are a compromise between ease of machining and the available calibration data.

For the specimens conforming to eqs (4) and (5), respectively,

$$
\begin{aligned}
& A_{\min }=\left[1.835+7.15 a_{0} / D+9.85\left(a_{0} / D\right)^{2}\right] \cdot(S / D) \quad \text { and } \\
& A_{\min }=24.0 \cdot\left[1-0.6 \Delta w / D+1.4 \Delta a_{0} / D-0.01 \Delta(2 \theta)\right] .
\end{aligned}
$$

The level I fracture toughness is then calculated from eq. (1) as

$$
K_{\mathrm{CB}} \quad \text { or } \quad K_{\mathrm{SR}}=A_{\min } F_{\max } / D^{1.5} \text {. }
$$

For a brittle material the fracture load $F_{\max }$ would coincide with $a=a_{\mathrm{m}}$.

Level II testing takes non-ideal material behaviour into account and specifies the evaluation of a correction of the fracture toughness value along the lines of Barker's[21] plasticity correction, which requires that load point displacement (LPD) measurements are made.

Assuming that the specimen compliance is a good measure of crack length there are three steps involved. The first step is a specification of how the compliance $\lambda_{\mathrm{F}}$ or stiffness $S_{\mathrm{F}}=1 / \lambda_{\mathrm{F}}$ is to be determined at a number of points on the $F$ vs LPD curve. Barker's[27] linearization procedure is specified (see Fig. 8). It assumes that a partial unloading cycle down to $0.1-0.2 \cdot F_{\max }$ is made for each point.

The final line of cycle $i$ has the slope $S_{\mathrm{F} i}$, its intersection with the smoothed $F$ vs LDP curve defines a point $F_{i}$ and its intersection with the LPD axis defines the residual LPD, $\delta_{F i}^{r}$.

The second step is finding the desired evaluation point $F_{\mathrm{m}}$ corresponding to $a=a_{\mathrm{m}}$, for which $S_{\mathrm{Fm}}=1 / \lambda_{\mathrm{F}}\left(a_{\mathrm{m}}\right)$. The specified way is depicted in Fig. 9. First find the two points with slope values that span $S_{\mathrm{Fm}}, F_{i-1}$ and $F_{i}$ say. Then find the point $F_{l}$ on the unloading line through $F_{i-1}$. It shall have the same amount of displacement recovery as $F_{i}$, i.e.

$$
l=\delta_{\mathrm{F} i}-\delta_{\mathrm{F} i}^{\mathrm{r}}=F_{i} / S_{\mathrm{F} i}=F_{l} / S_{\mathrm{F} i-1} .
$$

Then draw a straight line through $F_{i}$ and $F_{l}$ and find the interpolation point whose load is

$$
F_{\mathrm{e}}=S_{\mathrm{Fm}} \cdot l=F_{i} \cdot\left(S_{\mathrm{Fm}} / S_{\mathrm{F} i}\right)
$$

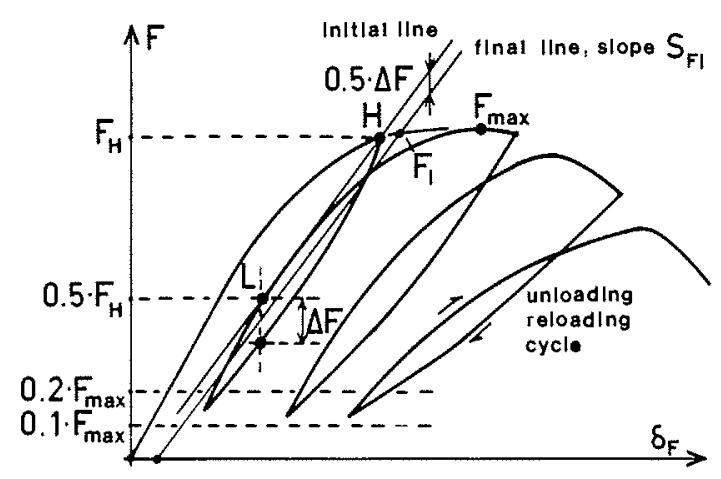

Fig. 8. Construction of linearized unloading line in $F$ vs LPD record.

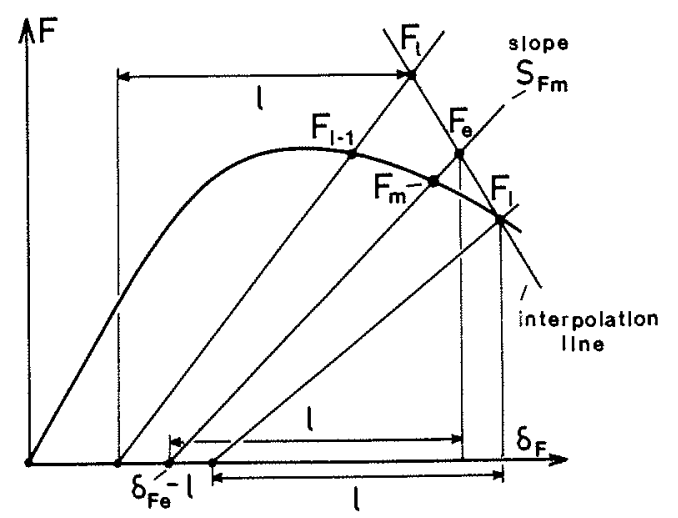

Fig. 9. Points relating to derivation of the point $F_{\mathrm{m}}$ at which the fracture toughness is evaluated. 
The corresponding displacement is $\delta_{\mathrm{Fe}}$. Next find the point $\left(\delta_{\mathrm{Fe}}-l, 0\right)$ on the LPD axis. Draw a straight line through it and $F_{\mathrm{e}}$. It will automatically have the slope $S_{\mathrm{Fm}}$. Let its intersection with a $F$ vs LPD curve, which has been smoothed to remove any dips due to the unloading reloading cycles, define the evaluation point $F_{\mathrm{m}}$ with coordinates $\left(\delta_{\mathrm{Fm}}, F_{\mathrm{m}}\right)$.

This procedure is a linear interpolation in terms of slope and contains a second order error term. In practice $S_{\mathrm{Fm}}$ is determined as $S_{\mathrm{Fm}}=S_{\mathrm{Fo}} \cdot s_{\mathrm{m}}$, the slope value of the initial tangent times the slope ratio, either

$$
\begin{aligned}
& s_{\mathrm{m}}=1.05-2.15 a_{0} / D+4.21\left(a_{0} / D\right)^{2} \text { for the CB or } \\
& s_{\mathrm{m}}=0.5 \text { for the SR. }
\end{aligned}
$$

If $F_{\mathrm{m}} \approx F_{\max }$, then $F_{\max }$ is used instead.

The third step concerns the non-linearity correction. To this end define first the average load $\bar{F}_{i}=\left(F_{i}+F_{i-1}\right) / 2$ (see Fig. 10). Next let this load define two matching displacements along the unloading lines through $F_{i-1}$ and $F_{i}$. Their difference

$$
\Delta \delta_{\overline{\mathrm{F}} i}=\delta_{\overline{\mathrm{F}} i}-\delta_{\overline{\mathrm{F}}_{i-1}} \text { and } \Delta \delta_{\mathrm{F} i}^{\mathrm{r}}=\delta_{\mathrm{F} i}^{\mathrm{r}}-\delta_{\mathrm{F} i-1}^{\mathrm{r}}
$$

are used to define $p$,

$$
p=\Delta \delta_{\mathrm{F} i}^{\Gamma} / \Delta \delta_{\overline{\mathrm{F}} i}
$$

(cf. Barker [21].)

The non-linearity corrected fracture toughness is then defined as

$$
K_{\mathrm{CB}}^{\mathrm{c}}=[(1+p) /(1-p)]^{0.5} K_{\mathrm{CB}} \quad \text { or } \quad[(1+p) /(1-p)]^{0.5} A_{\min } F_{\mathrm{m}} / D^{1.5}
$$

if $F_{\mathrm{m}} \neq F_{\max }$. An identical relation yields $K_{\mathrm{SR}}^{\mathrm{c}}$ from $K_{\mathrm{SR}}$. If the LPD measurements are calibrated then the SM:s also contain expressions for the non-dimensional compliance of the uncracked specimen, $g_{0}$, with which the Young's modulus may be determined from $E=S_{\mathrm{F} 0} g_{0} / D$ and then fracture toughness in $K$-terms can be converted to energy rate resistance.

The loading rate in LPD controlled testing and crack speed around $a=a_{\mathrm{m}}$ are related through

$$
\mathrm{LPD}=6.4 K_{\mathrm{CB}} /(E \sqrt{ } D) \cdot \dot{a}_{\mathrm{m}}
$$

for the Chevron Bend specimen. For the Short Rod the numerical prefactor is 17.0. It is specified that $\dot{a}_{\mathrm{m}} \geqslant 0.001 \mathrm{~m} / \mathrm{s}$ during testing so as to minimize the influence of subcritical crack growth on the fracture toughness measurements.

The Short Rod is sensitive to transverse tensile failure of the specimen arms. In order to avoid this the specimen size should fulfil

$$
D>1.15 \cdot\left(K_{\mathrm{SR}} / \sigma_{\mathrm{t}}\right)^{2}
$$

The Chevron Bend specimen is much less sensitive to this type of failure.

\section{RESEARCH SUPPORTING THE WORKING GROUP EFFORT}

The research which has supported the WG effort consists both of calibration of specimens and fracture toughness testing. The Chevron Bend expression for $A_{\min }$ in eq. (6) is based on an experimental calibration of three sets of specimens with the chevron apex $a_{0} / D=0.053,0.150$ and 0.248 [13].

Takahashi et al. $[28,29]$ have made an experimental calibration for $a_{0} D=0.205$ and the overall agreement is excellent (see Fig. 11). Their value, $A_{\min }=12.46$, is less than $1 \%$ higher than that predicted by eq. (6), $A_{\min }=12.37$.

Wai and $\mathrm{Li}[30]$ have made experimental calibrations for $a_{0} / D=0.05,0.10,0.15,0.20$ and 0.25 . Their resulting expression yields values for $A_{\min }$ which are skewed with respect to eq. (6), starting at $-2 \%$ increasing to $+6 \%$ at midrange and ending at $+8 \%$ as $a_{0} / D$ covers the range from 0.05 to 0.25 . This result may in part be due to their choice of functional form of the fitted compliance function, which was different. 


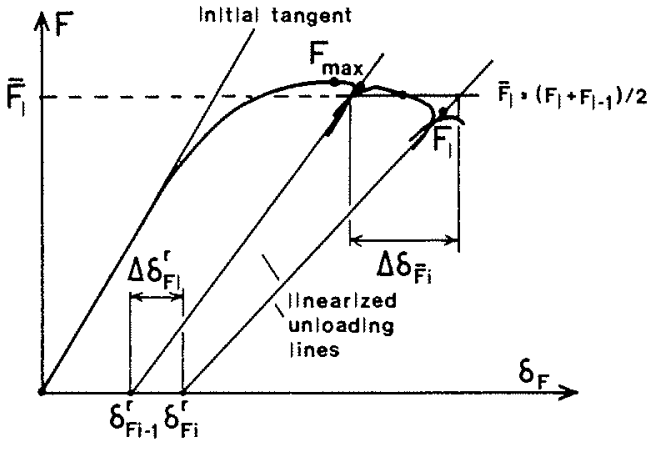

Fig. 10. Construction of non-linearlity correction factor $p$.

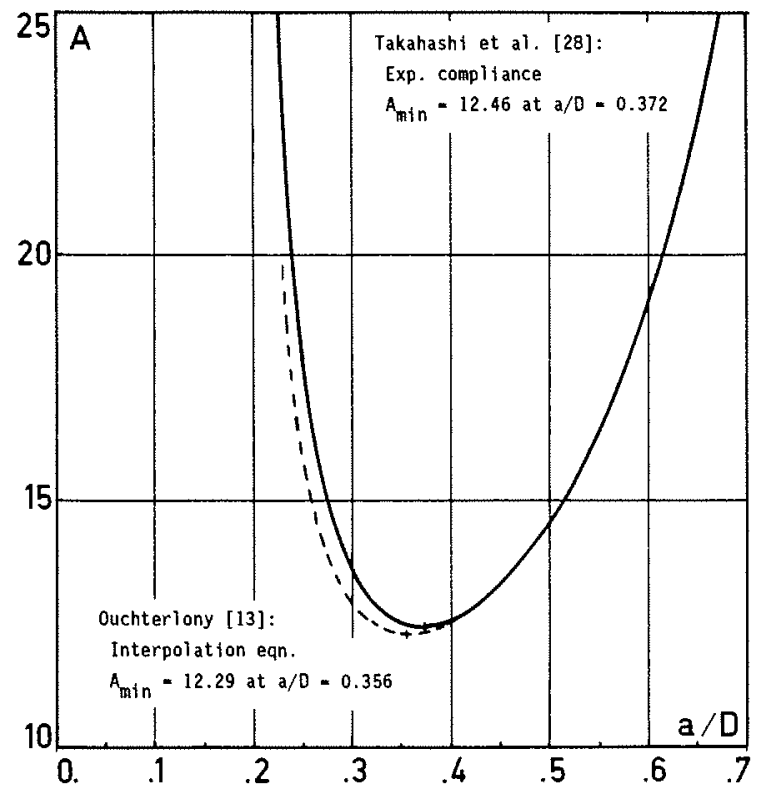

Fig. 11. Comparison of normalized stress intensity factor curves, $A$ vs crack length ratio $a / D$, for Chevron Bend specimen with $a_{0} / D=0.205$. Results based on experimental compliance calibrations.

Numerical calibrations of the Chevron Bend specimen have been made by Gerstle[31] and Ouchterlony[32] for $a_{0} / D=0.15$ and by Hayashi et al.[33] for $a_{0} / D=0.205$. As discussed in[32], the numerical $A_{\min }$ values for $a_{0} / D=0.15$ lie in the range 0 to $8 \%$ below eq. (6), see Fig. 12 . When errors are considered[32], and the $+6 \%$ of Wai and Li[30] are taken into account, $A_{\min }$ as predicted by eq. (6) lies exactly in the middle of an interval of uncertainty of $\pm 6 \%$. The combined results for $a_{0} / D=0.205[28-30,33]$ give a nearly identical result, so the bias of eq. (6) may be relatively small.

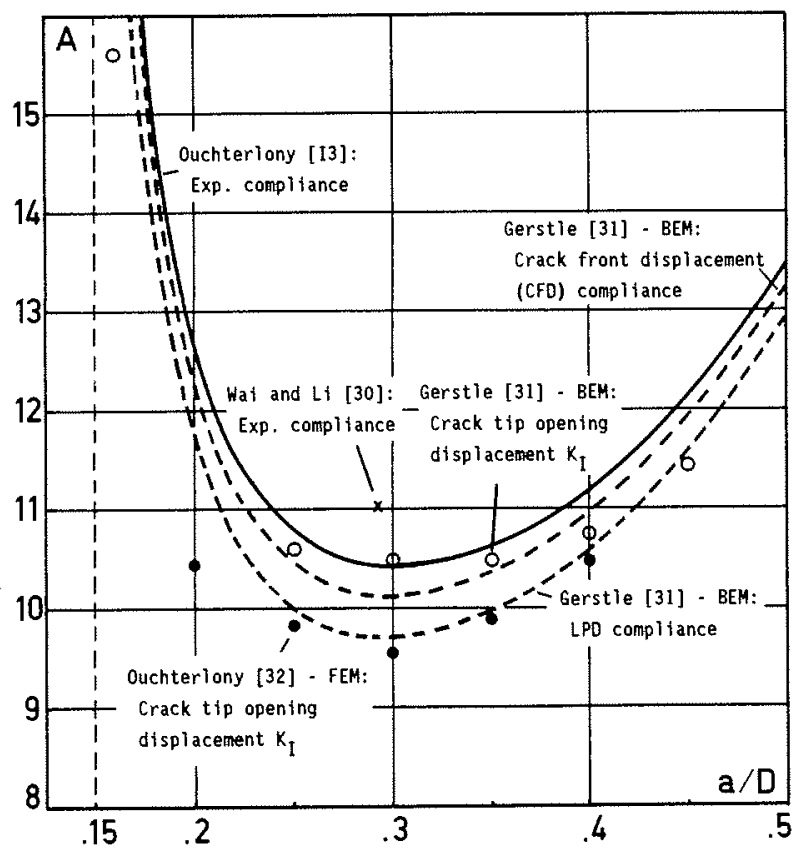

Fig. 12. Normalized stress intensity factor curves and computed values $A$ vs $a / D$, for Chevron Bend specimen with $a_{0} / D=0.15$. Results based mainly on numerical calibrations. 
The uncertainty (imprecision) is however larger than the error bounds of $A_{\min }$ for the Short Rod, the roughly $\pm 1 \%$ given in eq. (2), which was sufficient for the latter specimen to be used by the WG without further calibration work. Recently an extensive comparative numerical calibration of the Chevron Bend and Short Rod specimens of standard proportions was started at the Tohoku University in Japan[34]. In it Poisson's ratio values of $v=0.1,0.25$ and 0.4 are studied and the influence of $v$ on compliance and stress intensity factor does not seem to be best accounted for by standard plane strain or plane stress prefactors, but rather by $1-\beta v^{2}$ where $0<\beta<1$.

The preliminary results[34] tend to confirm the Short Rod formulas in the SM:s very well but not the Chevron Bend ones. Thus there is still room for a deeper analysis of all Chevron Bend calibration results, especially to determine why the numerically obtained stress intensity factor values are consistently lower than the experimental ones and if possible to narrow down the associated error bounds.

The amount of fracture toughness values obtained from testing with core based specimens with chevron notches is growing steadily. Table 1 contains a current list based mainly on work by

Table 1. Fracture toughness values obtained from core specimens, given as mean no.tests \pm std.dev. in $\mathrm{MN} / \mathrm{m}^{1.5}$

\begin{tabular}{|c|c|c|c|c|}
\hline \multirow[b]{2}{*}{ Rocks } & \multicolumn{2}{|c|}{ Chevron Bend } & \multicolumn{2}{|c|}{ Short Rod } \\
\hline & $K_{\mathrm{CB}}$ & $K_{\mathrm{CB}}^{\mathrm{c}}$ & $K_{\mathrm{SR}}$ & $K_{\mathrm{SR}}^{\mathrm{c}}$ \\
\hline Tampomas andesite[39] & $1.50_{7} \pm 0.12$ & $1.68_{7} \pm 0.15$ & - & - \\
\hline Tampomas andesite[39] & $1.26_{s} \pm 0.10$ & $1.26_{5} \pm 0.26$ & - & - \\
\hline Whin Sill dolerite[23] & - & - & $2.86_{6} \pm 0.12$ & $3.26_{6} \pm 0.09$ \\
\hline Kallax gabbro[37] & - & - & $2.22_{13} \pm 0.11$ & $2.58_{18} \pm 0.22$ \\
\hline Kallax gabbro[37] & - & - & $2.86_{10} \pm 0.14$ & $3.23_{13} \pm 0.34$ \\
\hline Bohus granite[36] & $1.46_{\mathrm{s}} \pm 0.07$ & - & $1.8_{3}$ & $2.4_{3}$ \\
\hline Bohus granite[25] & $1.69_{4} \pm 0.04$ & $1.42_{4} \pm 0.14$ & - & - \\
\hline Cornwall granite[35] & $1.32_{4} \pm 0.10$ & - & - & - \\
\hline Epprechtstein granite[35] & $1.74_{8} \pm 0.18$ & - & - & - \\
\hline Falkenberg granite[35] & $0.65_{4} \pm 0.14$ & - & - & 一 \\
\hline Falkenberg granite[35] & - & $1.52_{5} \pm 0.20$ & - & - \\
\hline Iidate granite[35] & $1.09_{s} \pm 0.13$ & $1.73_{s} \pm 0.21$ & - & - \\
\hline Iidate granite[28] & $1.37_{3} \pm 0.13$ & $2.26_{3} \pm 0.65$ & $1.01_{4} \pm 0.18$ & $1.12_{4} \pm 0.35$ \\
\hline Iidate granite $\mathrm{D}, \mathrm{A}[25]$ & $1.43_{3} \pm 0.01$ & $0.83_{3} \pm 0.13$ & $1.58_{3} \pm 0.08$ & $1.85_{3} \pm 0.06$ \\
\hline Iidate granite ST[25] & - & - & $1.11_{3} \pm 0.12$ & $1.26_{3} \pm 0.18$ \\
\hline Kråkemåla granite[36] & $1.64_{3} \pm 0.04$ & $2.16_{3} \pm 0.23$ & $1.69_{6} \pm 0.17$ & $2.22_{s} \pm 0.24$ \\
\hline Merrivale granite[23] & - & - & $1.50_{24} \pm 0.10$ & $1.80_{24} \pm 0.13$ \\
\hline Pink granite[23] & - & - & $1.58, \pm 0.04$ & $2.03_{4} \pm 0.08$ \\
\hline Răsjö granite[25] & - & - & $2.37_{6} \pm 0.32$ & $2.80_{6} \pm 0.33$ \\
\hline Strath Halladale granite[23] & - & - & $1.80_{11} \pm 0.10$ & $2.19_{11} \pm 0.11$ \\
\hline Stripa granite[19] & - & - & $2.01_{5} \pm 0.14$ & $2.36_{11} \pm 0.13$ \\
\hline Stripa granite[36] & - & - & $2.37, \pm 0.15$ & $2.70_{9} \pm 0.27$ \\
\hline Westerly granite[23] & - & - & $1.64_{9} \pm 0.03$ & $1.82_{9} \pm 0.07$ \\
\hline Westerly granite[24] & - & - & $2.28_{17} \pm 0.19$ & - \\
\hline Westerly granite[36] & - & - & $2.04_{4} \pm 0.05$ & $2.27_{4} \pm 0.03$ \\
\hline Finnsjön granodiorite[25] & - & - & $2.95_{3} \pm 0.11$ & $3.35_{3} \pm 0.08$ \\
\hline Grey norite[23] & - & - & $2.23_{11} \pm 0.11$ & $2.69_{6} \pm 0.16$ \\
\hline Ogino tuff[38] & $1.05_{17} \pm 0.11$ & $1.08_{9} \pm 0.10$ & $1.02_{19} \pm 0.05$ & $1.06_{19} \pm 0.05$ \\
\hline Pennant sandstone[23] & - & - & $1.98_{6} \pm 0.06$ & $2.56_{6} \pm 0.07$ \\
\hline Ruhr sandstone[35] & $1.03_{10} \pm 0.04$ & - & - & - \\
\hline Älvdalen sandstone[25] & $1.51_{6} \pm 0.08$ & $0.73_{6} \pm 0.08$ & $1.54_{11} \pm 0.08$ & $1.91_{11} \pm 0.14$ \\
\hline Indiana limestone[20] & - & - & $0.90_{7} \pm 0.11$ & $1.13_{7} \pm 0.09$ \\
\hline Indiana limestone[24] & - & - & $1.05_{9} \pm 0.06$ & - \\
\hline Klinthagen limestone[36] & $1.31_{2}$ & - & $1.41_{8} \pm 0.19$ & $1.87_{g} \pm 0.25$ \\
\hline Shelly limestone[23] & - & - & $1.40_{5} \pm 0.03$ & $1.44_{s} \pm 0.04$ \\
\hline Anvil Points oil shale $\mathrm{D}[22]$ & - & - & $0.56_{s} \pm 0.09$ & $1.02_{3} \pm 0.14$ \\
\hline Anvil Points oil shale ST[22] & - & - & $0.25_{4} \pm 0.04$ & $0.47_{2} \pm 0.07$ \\
\hline Carrara marble[35] & $1.26, \pm 0.08$ & $1.38_{5} \pm 0.09$ & - & - \\
\hline Ekeberg marble[36] & $1.89_{16} \pm 0.12$ & - & $1.83_{9} \pm 0.35$ & $2.25_{9} \pm 0.36$ \\
\hline Ekeberg marble ST[36] & - & - & $1.48_{3} \pm 0.16$ & $1.82_{3} \pm 0.10$ \\
\hline Ekeberg marble D[36] & - & - & $2.28_{2} \pm 0.01$ & $2.62_{2} \pm 0.05$ \\
\hline Ekeberg marble[25] & $1.79_{4} \pm 0.07$ & $1.76_{4} \pm 0.21$ & - & - \\
\hline Treuchtlingen marble[35] & $1.26_{6} \pm 0.07$ & $1.70_{6} \pm 0.09$ & - & - \\
\hline Yizhang marble[40] & $1.49_{7} \pm 0.09$ & $1.83_{7} \pm 0.18$ & - & - \\
\hline
\end{tabular}

†Notes. A, D and ST mean arrester, divider and short transverse orientations of crack with respect to discernible structure in rock (see Fig. 6). 


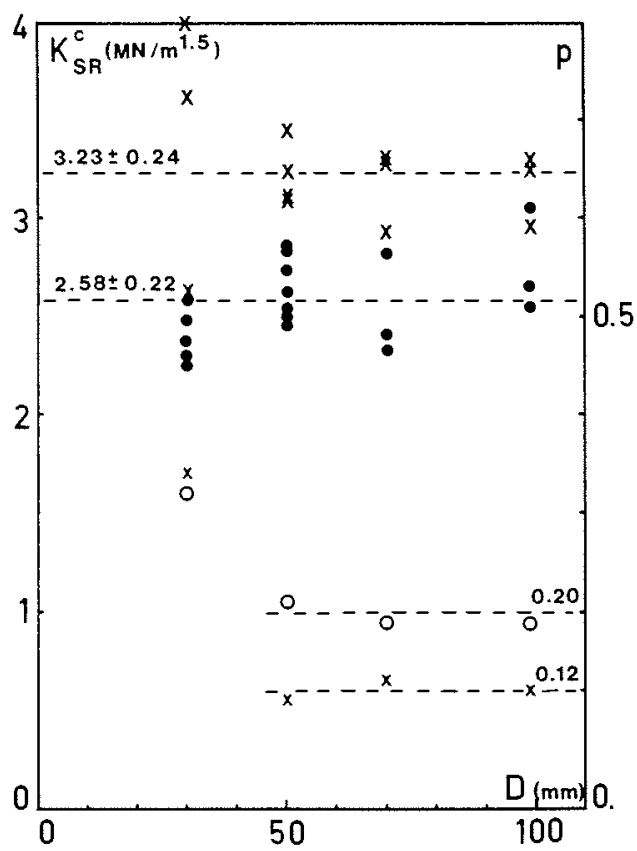

Fig. 13. Level II, non-linearity corrected, fracture toughness $\left(K_{\mathrm{SR}}^{\mathrm{c}}\right)$ and non-linearity correction factor $(p)$ values for two sets of Kallax gabbro. After Yi[37].

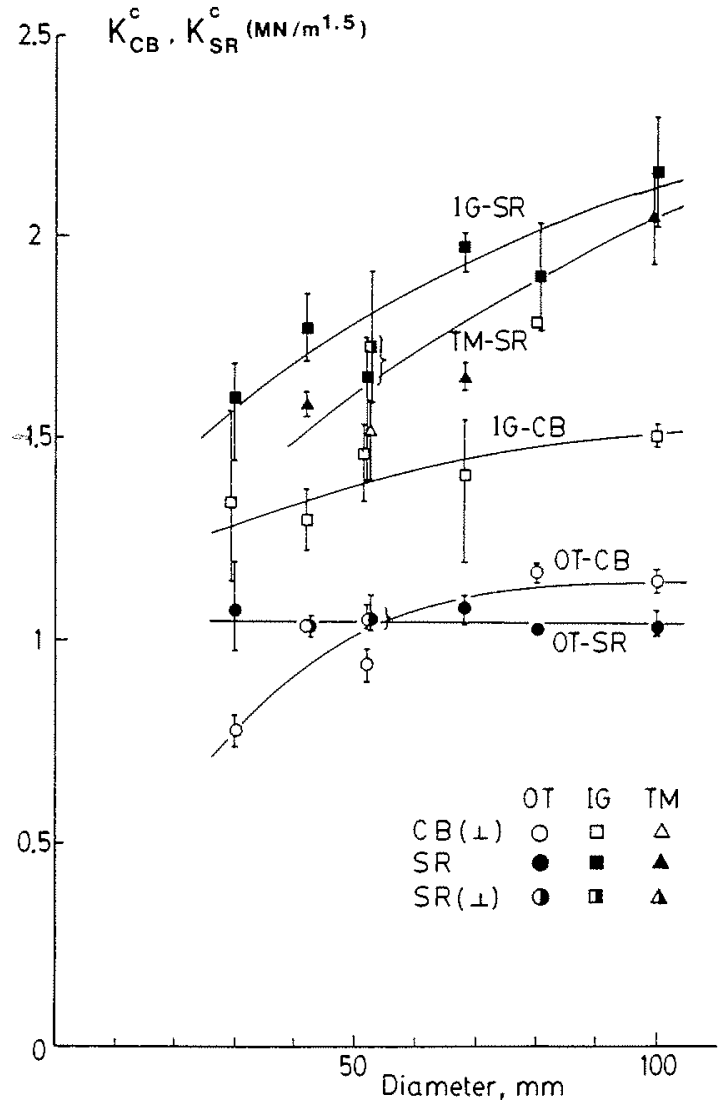

Fig. 14. Level II, non-linearity corrected, fracture toughness values from Short Rod (SR) and Chevron Bend (CB) tests on Ogino tuff (OG), Inada granite (IG) and Tohoku marble (TM). After Matsuki et al.[38].

researchers engaged in the development of the SM:s. The data base will of course increase rapidly after these[25] become generally available.

The testing and the evaluation have been made essentially in agreement with the contents of the final document. The results primarily indicate the range of values to be expected, the scatter obtained in testing and the variability and anisotropy present in rock material. The testing was made on specimens with diameters from $D=25$ to $100 \mathrm{~mm}$ roughly and Table 1 substantiates the earlier conclusion[36] that level II testing hardly can be avoided if a representative fracture toughness value is desired. Present $p$-values range up to 0.5 and above.

Concerning the question whether corrected fracture toughness values depend on specimen size or not, the previously reported size independence for Indiana limestone[20] and Stripa granite[19] has been verified also for Kallax gabbro[37] and Ogino tuff[38], whereas for Inada granite and Tohoku marble[38] $K_{\mathrm{CB}}^{\mathrm{c}}$ and $K_{\mathrm{SR}}^{\mathrm{c}}$ increase with increasing specimen size (see Figs 13 and 14). It is noteworthy that $p$ for all rocks simultaneously seems to level off at a nonzero value.

The results for Inada granite[38] could be interpreted as an $R$-curve effect (see Fig. 15), i.e. that the crack in the test specimen has not reached a representative toughness level at the evaluation point. Further experimental work at the Tohoku University[41] on a suite of 11 rocks aim at producing size requirements like eq. (3) and validity recommendations for the chevron notched specimens of the SM:s.

A preliminary evaluation shows that the $R$-curve behavior for practical purposes is nearly independent of specimen type and that

$$
a_{\mathrm{m}}-a_{0} \geqslant 0.2-0.3 \cdot\left(K_{\mathrm{lc}} / \sigma_{\mathrm{t}}\right)^{2}
$$




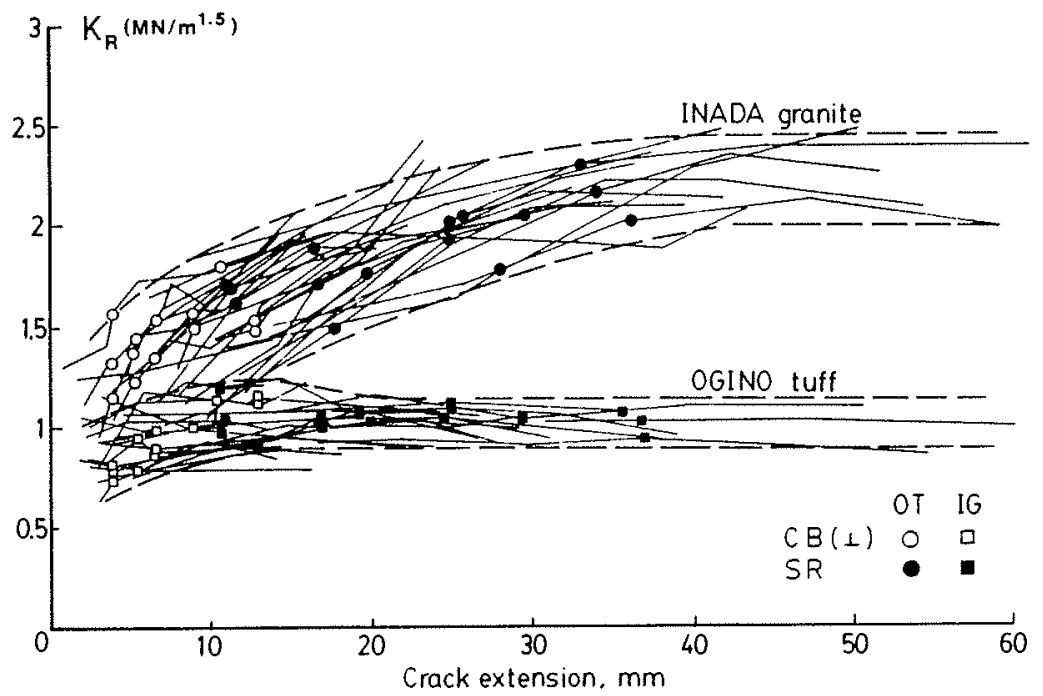

Fig. 15. Crack extension resistance curves, $K_{\mathrm{R}}\left(a-a_{0}\right)$, for specimens of Ogino tuff and Inada granite. Circles and squares denote evaluation points $\left(a_{\mathrm{m}}\right)$ and corresponding $K_{\mathrm{CB}}^{\mathrm{c}}$ (open symbols) and $K_{\mathrm{SR}}^{\mathrm{c}}$ (filled symbols) values.

may be a sufficient amount of subcritical crack growth. Since $a_{\mathrm{m}}-a_{0} \approx 0.15 D$ for the Chevron Bend specimen and about $0.34 \mathrm{D}$ for the Short Rod there would follow the size requirements

$$
\begin{aligned}
& D_{\mathrm{SR}} \geqslant 0.6-0.9 \cdot\left(K_{\mathrm{lc}} / \sigma_{\mathrm{t}}\right)^{2} \\
& D_{\mathrm{CB}} \geqslant 1.3-2.0 \cdot\left(K_{\mathrm{lc}} / \sigma_{\mathrm{t}}\right)^{2} .
\end{aligned}
$$

Further, it seems as if soft rocks meet these requirements more readily than hard rocks. The $R$-curve behavior would also explain why $K_{\mathrm{CB}}>K_{\mathrm{CB}}^{\mathrm{c}}$ in some cases in Table 1 .

Table 1 shows that the compatibility of fracture toughness data from Chevron Bend and Short Rod testing probably has not been sufficiently investigated, although the work of Matsuki et al.[38] is affirmative regarding such compatibility. One way to avoid the $R$-curve complication involved would be to define a new evaluation point in the Chevron Bend specimen, one for which the amount of crack growth is $0.34 D$ like in the Short Rod.

Work by $\mathrm{Li}$ and Wai[40] on Yizhang marble has given the result that Chevron Bend testing results $\left(K_{\mathrm{CB}}^{\mathrm{c}}\right)$ are consistent with values from bend specimens with straight notches, just as was the case for Short Rod testing of Stripa granite[19].

The influence of anisotropy is presently being investigated jointly by the Tohoku University and the Swedish Detonic Research Foundation for Iidate granite and Älvdalen sandstone. A broader interlaboratory study with many participants is a desirable next step such that the performance of the SM:s can be expressed in terms of repeatability and reproduciblity.

\section{PARALlel DeVElopMent AND CONCLUSION}

During the time that the ISRM WG has been working, the development of core based specimens and testings methods has of course continued elsewhere. Specimen development includes the burst test, Kim and Mubeen[42], a semi-circular bend specimen, Chong et al.[43, 44], a modified ring test, Thiercelin and Roegiers[45], and a modified disc test, Czoboly et al.[45]. (See Fig. 16.)

In all of these specimens the direction of crack extension is the same, i.e. radial from the cylindrical surface. Thus supplementing the Chevron Bend and Short Rod specimens with one of them, would give a set of three specimens with mutually perpendicular crack extension directions from which the toughness anisotropy could be completely determined using only one coring direction.

Three lines of crack extension resistance testing will be mentioned. Hashida et al.[29] have used a $J$-integral approach and acoustic emission techniques to pin point a critical value, $J_{\mathrm{iAE}}$, for the 


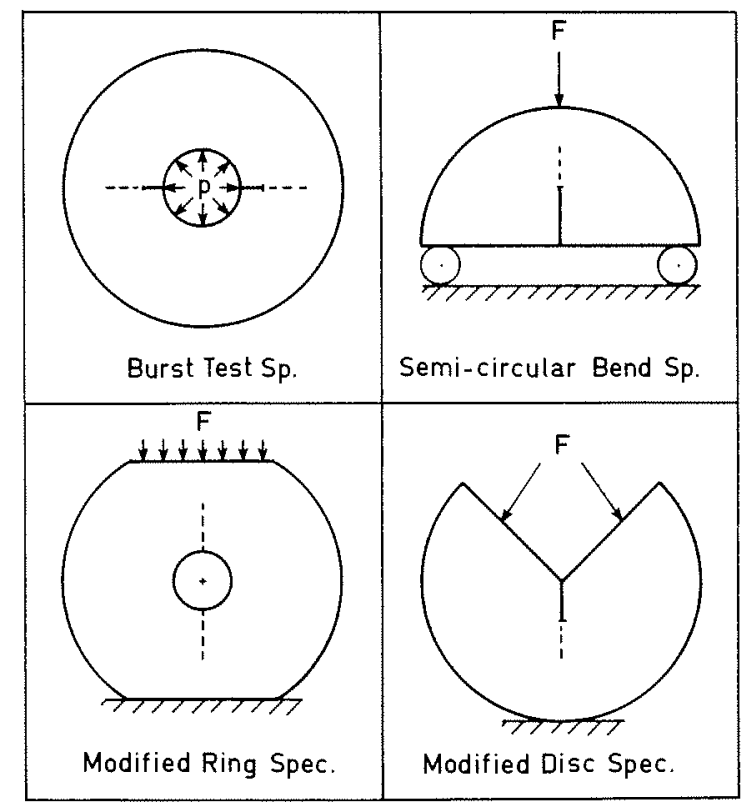

Fig. 16. Circular or core based specimens used in the fracture toughness testing of rock: (1) Burst test specimen[14, 42]. (2) Semi-circular bend specimen[43, 44]. (3) Modified ring specimen[45]. (4) Modified disc specimen[46].

initiation of crack growth from straight notches in virgin material. Since $J_{\mathrm{iAE}}$ is reasonably constant for a wide range of specimen types and sizes for the low modulus Iidate granite, this method would seem to have a potential for a wide variety of rocks. (See also Takanohashi et al.[47].)

The draft recommendations of RILEM for concrete[48], in which the fracture energy $G_{\mathrm{F}}$ is measured, is the second line. The fracture energy is justified by the postulated existence of a finite cohesive line zone at a crack tip (Hillerborg[49]). Such a zone has been shown to exist in rock (Labuz et al.[50]).

$G_{\mathrm{F}}$ is given by the work per unit area $\left(\mathrm{J} / \mathrm{m}^{2}\right)$ which is required to completely divide (fracture) an element of material. It is, in principle measured exactly as $\bar{R}$, which for rock depends on specimen size and crack length $[4,12]$. The results for concerete show that $G_{\mathrm{F}}$ on average increases by $30 \%$ when specimen size increases three fold (Hillerborg[51]). The variations in fracture toughness of rock with specimen size in the research related above is in most cases substantially smaller.

A third line is the $J$-integral related work on concrete by Leung and Li[51]. They measure the whole cohesive force vs crack opening displacement curve, the area of which equals $G_{\mathrm{F}}$, by using two specimens with slightly different initial crack lengths. They maintain that their differential energy measurements could largely eliminate the irrecoverable losses outside the cracking plane, thus greatly reducing the size dependence of $G_{\mathrm{F}}$.

It appears that the fracture toughness values produced by the chevron notched specimens of the ISRM Standard (SM:s) are reasonably compatible with another and with values from other tests. They can further be independent of specimen size and crack length. $G_{\mathrm{F}}$ or $\bar{R}$ values are neither compatible with other values nor size independent, as far as present testing goes.

If a single value representing the crack extension resistance of rock is sought, $K_{\mathrm{CB}}^{\mathrm{c}}$ and $K_{\mathrm{SR}}^{\mathrm{c}}$ and possibly $J_{\mathrm{iAE}}$ thus appear to be superior to $G_{\mathrm{F}}$ and $\bar{R}$. Since there is good experimental and theoretical justification for both approaches, a comparison including test methods is in place. It should at this stage emphasize real material behavior over theoretical analysis based on assumed behavior (see Hassanzadeh and Hillerborg[53]).

Acknowledgements - The author expresses his gratitude to his colleagues in the ISRM working group without whose active support the Suggested Methods for Determining the Fracture Toughness of Rock would never have materialized. The first rate support of Profs Takahashi and Matsuki and their colleagues at the Tohoku University in Sendai, Japan, during the present testing phase is deeply appreciated. 


\section{REFERENCES}

[1] H. P. Rossmanith (Ed.), Rock Fracture Mechanics, CISM Courses and Lectures No. 275. Springer, Wien (1983).

[2] Z. P. Bazănt (Ed.), Mechanics of Geomaterials-Rocks, Concretes, Soils. Wiley, Chichester (1985).

[3] B. K. Atkinson (Ed.), Fracture Mechanics of Rock. Academic Press, London (1987).

[4] F. Ouchterlony, Review of fracture toughness testing of rock. SM Arch. 7, 131 (1982).

[5] C. C. Barton, Variables in fracture energy and toughness testing of rock. Proc. 23rd U.S. Symp. Rock Mechanics (Edited by R. E. Goodman and F. E. Heuze), pp. 449-462. AIME, New York (1982).

[6] M. G. Karfakis, K. P. Chong and M. D. Kuruppu, A critical review of fracture toughness testing of rock. Proc. 27th U.S. Symp. on Rock Mechanics (Edited by H. L. Hartman), pp. 3-10. SME, Littleton, Colorado (1986).

[7] L. M. Barker, A simplified method for measuring plane strain fracture toughness. Engng Fracture Mech. 9, 361 (1977).

[8] J. C. Newman, Jr, A Review of Chevron-Notched Fracture Specimens. ASTM STP 855 (Edited by J. H. Underwood et al.), pp. 5-31 (1984).

[9] R. T. Bubsey, D. M. Fischer, M. H. Jones and J. E. Srawley, Compliance measurements, in Fracture Mechanics, (Edited by A. S. Kobayashi), pp. 76-95. SESA, Westport, Connecticut (1973).

[10] F. Ouchterlony, Extension of the compliance and stress intensity formulas for the single edge crack round bar in bending, ASTM STP 745 (Edited by S. W. Freiman and E. R. Fuller, Jr), pp. 237-256, (1981).

[11] F. Ouchterlony, A new core specimen for the fracture toughness testing of rock. SveDeFo Report DS 1980:17, Swedish Detonic Research Foundation, Stockholm, Sweden (1980).

[12] F. Ouchterlony, Fracture toughness testing of rock, in Rock Fracture Mechanics, CISM Courses and Lectures No. 275 (Edited by H. P. Rossmanith) pp. 69-150. Springer, Wien (1983).

[13] F. Ouchterlony, A core bend specimen with chevron edge notch for fracture toughness measurements. Proc. 27th U.S. Symp. on Rock Mechanics (Edited by H. L. Hartmann), pp. 177-184. SME, Littleton, Colorado (1986).

[14] A. S. Abou-Sayed, An experimental technique for measuring the fracture toughness of rock under downhole stress conditions. VDI-berichte No. 313, pp. 819-824 (1978).

[15] H. Awaji and S. Sato, Combined mode fracture toughness measurements by the disc test. J. Engng Mater. Technol. 100, $175(1978)$.

[16] J. C. Newman, Jr, Stress intensity factors and crack-opening displacemnts for round compact specimens. Int. J. Fracture 17, 567 (1981).

[17] F. Ouchterlony and Z. Sun, New methods of measuring fracture toughness on rock cores. Proc. 1st Int. Symp. on Rock Fragmentation by Blasting (Edited by R. Holmberg and A. Rustan), Vol. 1, pp. 199-223. Luleå University of Technology, Luleå, Sweden (1983).

[18] Z. Sun, Fracture mechanics and tribology of rocks and rock joints. Doctoral Thesis 1983:22D, Luleå University of Technology, Luleå Sweden (1983).

[19] Z. Sun and F. Ouchterlony, Fracture toughness of stripa granite cores. Int. J. Rock Mech. Min. Sic. Geomech. Abstr. 23, 399 (1986).

[20] L. M. Barker, $K_{\mathrm{Ic}}$ Measurements using short rod specimens-the elastic plastic case. Terra Tek Report 77-91R, Salt Lake City, Utah (1977).

[21] L. M. Barker, Theory for determining $K_{\mathrm{lc}}$ from small, non-LEFM specimens, supported by experiments on aluminum. Int. J. Fracture 15, 515 (1979).

[22] L. S. Costin, Static and Dynamic Fracture Behavior of Oil Shale ASTM STP 745 (Edited by S. W. Freiman and E. R. Fuller, Jr.), pp. 169-184 (1981).

[23] P. G. Meredith, A fracture mechanics study of experimentally deformed crustal rocks. Unpublished Ph.D. Thesis, University of London (1983).

[24] A. R. Ingraffea, K. L. Gunsallus, J. F. Beech and P. P. Nelson, A Short-rod Based System for Fracture Toughness Testing of Rock. ASTM STP 855 (Edited by J. H. Underwood et al.), pp. 152-166 (1984).

[25] ISRM, Suggested methods for determining the fracture toughness of rock, F. Ouchterlony working group coordinator. Int. J. Rock Mech. Min. Sci. Geomech. Abstr. 25, 71 (1988).

[26] F. Ouchterlony, On the background to the formulae and accuracy of fracture toughness measurements with ISRM standard core specimens. Int. J. Rock Mech. Min. Sci. Geomech. Abstr. 26, 13 (1989).

[27] L. M. Barker, Data analysis methods for short rod and short bar fracture toughness tests of metallic materials. Terra Tek Report TR 80-12, Salt Lake City, Utah (1980).

[28] H. Takahashi, T. Hashida and T. Fukazawa, Fracture toughness tests by use of core base specimens. Research report no. T-002-86, Research Group of Geothermal Energy Extraction Engineering, Tohoku University, Sendai, Japan (1986).

[29] T. Hashida, T. Fukazawa and H. Takahashi, Fracture toughness testing of core based specimens by means of acoustic emission technique-ISRM fracture toughness test. Proc. SEM/RILEM Int. Conf. on Fracture of Concrete and Rock (Edited by S. P. Shah and S. E. Swartz), p. 389. SEM, Bethel, Connecticut (1987).

[30] Y. Wai and C. Li, Compliance calibration of chevron-notched round bar in bending. Proc. SEM/RILEM Int. Conf. on Fracture of Concrete and Rock (Edited by S. P. Shah and S. E. Swartz), pp. 273-279, SEM, Bethel, Connecticut (1987).

[31] W. H. Gerstle, Finite and boundary element modeling of crack propagation in two- and three-dimensions using interactive computer graphics, Dept. Structural Engng., Ph.D. Thesis, p. 220, Cornell University, Ithasca, New York (1985).

[32] F. Ouchterlony, A FEM calibration of a core bend specimen with chevron edge notch for fracture toughness measurements. SveDeFo Report DS 1987:11, Swedish Detonic Research Foundation, Stockholm, Sweden (1987).

[33] K. Hayashi, A. Ono and H. Abé, BEM analysis of a cylindrical three point bend specimen with a chevron crack for fracture toughness test of rock. To appear in Trans. Japan Soc. Mech. Engrs.

[34] K. Matsuki, Stress intensity factor and compliance for the chevron bend and short rod specimens, calculated by 3D-BEM. Personal communication, Tohoku University, Sendai, Japan, (1988).

[35] W. Müller and F. Rummel, Bruchzähigkeitsmessungen an Gesteinen. Bericht zu den BMFT-FE-Vorhaben 03E-3068-B, p. 133, Ruhr University, Bochum, FRG, (1984) (In German with English summary). 
[36] F. Ouchterlony, A presentation of the ISRM suggested methods for determining fracture toughness of rock material. Proc. 6th Int. Congress on Rock Mechanics (ISRM) (Edited by G. Herget and S. Vongpaisal), Vol. 2, pp. 1181-1185, Balkema, Rotterdam (1987).

[37] X. Yi, Fracture toughness and crack growth in short rod specimens of rocks. Licentiate Thesis: 1987:06L, Luleå University of Technology, Luleå, Sweden (1987).

[38] K. Matsuki, Y. Nozuyama and H. Takahashi, Size effect in the fracture toughness testing of rocks using a boring core. Proc. Spring Meeting Min and Metallurgical Institute Japan, pp. 193-194 (1988) (In Japanese).

[39] S. Abrahamsson, B. Niklasson and F. Ouchterlony, Fragmentation monitoring of production blasts at Mrica. SveDeFo Report DS 1987:6, Swedish Detonic Research Foundation, Stockholm, Sweden (1987).

[40] $\mathrm{C}$. Li and Y. Wai, Determination of fracture toughness of a marble with round bar specimen. Submitted to Int. J. Rock Mech. Min. Sci. Geomech. Abstr.

[41] K. Matsuki, Size and shape effects in fracture toughness testing of rocks according to suggested methods and necessary specimen size to obtain inherent fracture toughness. Personal communication, Tohoku University, Sendai, Japan (1988).

[42] A. Mubeen and K. Kim, Cylindrical specimens for $K_{\text {kc }}$ of rocks. Int. J. Mech. Sci. 27, 711 (1985).

[43] K. P. Chong and M. D. Kuruppu, New specimen for fracture toughness determination for rock and other materials. Int. J. Fracture 26, R59 (1984).

[44] K. P. Chong, M. D. Kuruppu and J. S. Kuszmaul, Fracture toughness determination of new materials. Engng Fracture Mech. 28, 43 (1987).

[45] M. Thiercelin and J. C. Roegiers, Fracture toughness determination with the modified ring test. Proc. 27th U.S. Symp. on Rock Mechanics, (Edited by H. L. Hartmann), pp. 615-622. SME, Littleton, Colorado (1986).

[46] E. Czoboly, M. Gálos, I. Havas and F. Thamm, Appropriate fracture mechanics specimens for testing rocks. Proc. 6th Biennial Eur. Conf. on Fracture, ECF6, (Edited by H. C. van Elst and A. Bakker), Vol. 3, pp. 2105-2114. Engng. Mtrls. Adv. Services, Warley, U.K. (1987).

[47] M. Takanohashi, S. Miyazaki and H. Takahashi, Evaluation of fracture toughness in the presence of pressurized water at elevated temperatures by means of the AE technique. JSME Int. J. 30, 754 (1987).

[48] RILEM Draft Recommendation, Determination of the fracture energy of mortar and concrete by means of three-point bend tests on notched beams. Mater. Struct. 18, (1985).

[49] A. Hillerborg, The theoretical basis of a method to determine the fracture energy $G_{\mathrm{F}}$ of concrete. Mater. Struct. 18, (1985).

[50] J. F. Labuz, S. P. Shah and C. H. Dowding, The fracture process zone in granite: evidence and effect. Int. J. Rock Mech. Min. Sci. Geomech. Abstr. 24, 235 (1987).

[51] A. Hillerborg, Results of three comparative test series for determining the fracture energy $G_{\mathrm{F}}$ of concrete. Mater. Struct. 18, (1985).

[52] C. Leung and V. C. Li, Determination of fracture toughness parameter of quasi-brittle materials with laboratory size specimens. Proc. SEM/RILEM Int. Conf. on Fracture of Concrete and Rock (Edited by S. P. Shah and S. E. Swartz), pp. 695-709, SEM, Bethel, Connecticut (1987).

[53] M. Hassanzadeh and A. Hillerborg, Theoretical analysis of test methods. Proc. SEM/RILEM Int. Conf. on Fracture of Concrete and Rock (Edited by S. P. Shah and S. E. Swarz), pp. 623-630 (1987) 